\title{
LARGE-SCALE INVESTIGATIONS OF THE DEFORMATION BEHAVIOUR OF LAYERS OF ICE SHELVES
}

\author{
by
}

\author{
Hans L. Jessberger and Rudolf Dörr
}

(Ruhr-Universität Bochum, Universitätstrasse 150, 4630 Bochum, West Germany)

\section{ABSTRACT}

For the investigation of time-dependent vertical deformation of upper layers of ice shelves loaded by accumulated snow and/or structures a large-scaie field test was started in 1980-81 at Georg von Neumayer station $\left(70^{\circ} 37^{\prime} \mathrm{S}, 8^{\circ} 22^{\prime} \mathrm{W}\right)$, Antarctica. Specially developed base plugs were fixed to the bottoms of 5.0 and $10.0 \mathrm{~m}$ deep bore holes by melting and refreezing the surrounding firn. The deformations of the snow firn layers will be measured between these base plugs and metal plates placed on the snow surface during installation. The bore holes are kept open by tubes of different diameters in order to allow for load-induced vertical deformations of snow and firn. Some measurements are directly affected by the presence of the station. The design of the measuring device, the procedure of installation, and the measurement of deformation are described. The results of calculations of deformation and measurements of first settlement are presented.

\section{INTRODUCTION}

During the German Antarctic Expedition in 1980-81 a research programme was begun for the investigation of the time-dependent vertical deformation of the upper layers of ice shelves. This depends on the rheological behaviour of the snow or firn. The equipment for long-term observation was installed during the construction of Georg von Neumayer station $\left(70^{\circ} 37^{\prime} \mathrm{S}, 8^{\circ} 22^{\prime} \mathrm{W}\right)$ on Ekstrobm I ce Shelf.

Using an extensiometer the vertical deformation of these upper layers caused by snow accumulation and/or the dead weight of structures will be observed during the next decade. The measuring points are located underneath and outside the buildings.

The snow and firn layers under consideration are now 5 to $10 \mathrm{~m}$ deep, and after 10 a they may $1 \mathrm{ie}$ approximately 12 to $20 \mathrm{~m}$ deep, depending on snow accumulation and drift. During the season 1981-82 the installation of measuring devices is planned at 30 to $50 \mathrm{~m}$ depths in order to study ice layers.

The test methods and the measuring device are described. First settlement data are analysed and compared with deformations computed under the assumption of constant compressive viscosity.

\section{DENSITY-DEPTH RELATIONSHIP}

The general increase of snow density with depth results from compression of snow by the load of the annual accumulation. This density increase will occur also from other loads such as structures. Snow density is an important factor governing the mechanical behaviour of snow, firn, and ice including the compressive viscosity $\eta_{1}$.

During the 1980-81 expedition cores were taken from bore holes down to $12 \mathrm{~m}$ on the Ekstrbm Ice Shelf. The density of the snow samples to $10 \mathrm{~m}$ depth is shown in Figure 1 as depth-density curve b.

In addition density values from Maudheim station $\left(71^{\circ} 03^{\prime} \mathrm{S}, 10^{\circ} 55^{\prime} \mathrm{W}\right)$ are plotted in Figure 1 , curve a (Mellor 1961). The reasonably good fit of both curves may be caused by similar climatic conditions at both places as far as the mean annual temperature and the annual snow accumulation is concerned. The values in Table I are taken from Mellor (1961) and Reinwarth and others (1982).

Fig.1, curve $c$, gives some information on the variation with depth of the maximum grain size.

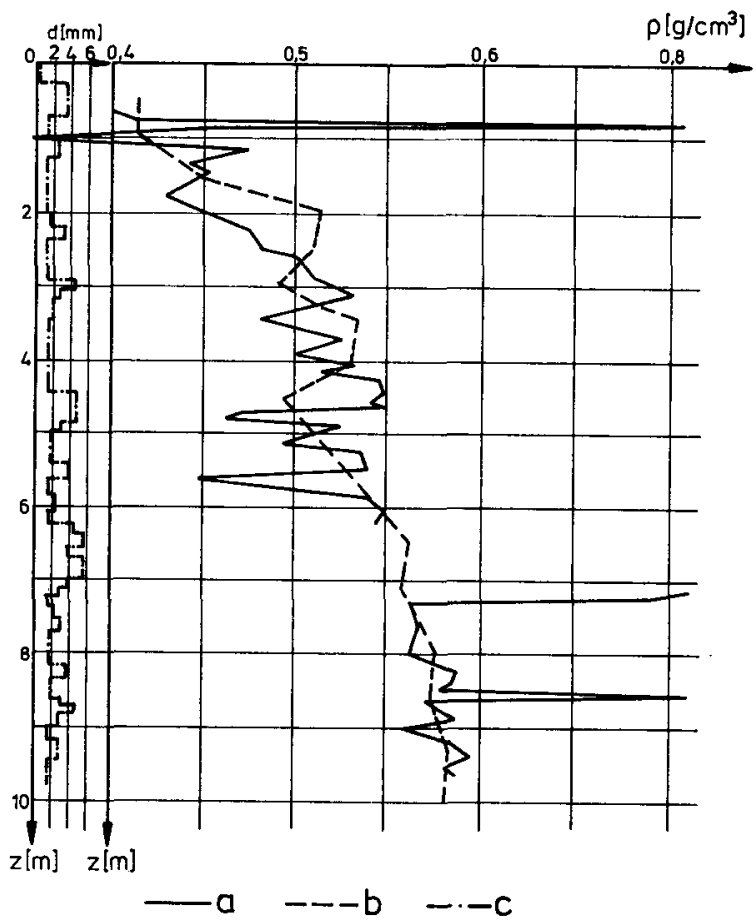

Fig.1. Depth-density curves: (a) Maudheim station, (b) Georg von Neumayer station, (c) stratigraphy at Georg von Neumayer station. 
TABLE 1. MEAN ANNUAL TEMPERATURE AND ANNUAL SNOW ACCUMULATION AT MAUDHEIM STATION AND GEORG VON NEUMAYER STATION

\begin{tabular}{lcc} 
& $\begin{array}{c}\text { Maudheim } \\
\text { station }\end{array}$ & $\begin{array}{c}\text { G.v. Neumayer } \\
\text { station }\end{array}$ \\
\hline $\begin{array}{l}\text { Mean annual } \\
\text { temperature }\end{array}$ & $-17^{\circ} \mathrm{C}$ & $-17.3^{\circ} \mathrm{C}$ \\
$\begin{array}{l}\text { Annual snow } \\
\text { accumulation }\end{array}$ & $\sim 75 \mathrm{~cm}$ & $\sim 73 \mathrm{~cm}$
\end{tabular}

Besides the general increase of density with depth considerable discontinuities were found in the snow stratigraphy (Reinwarth and others 1982).

\section{TEST METHOD}

The measuring device specially developed for this in situ investigation of vertical deformation is shown schematically in Figure $2(a)$ and after installation in Figure $2(b)$. Essential parts of the extens-

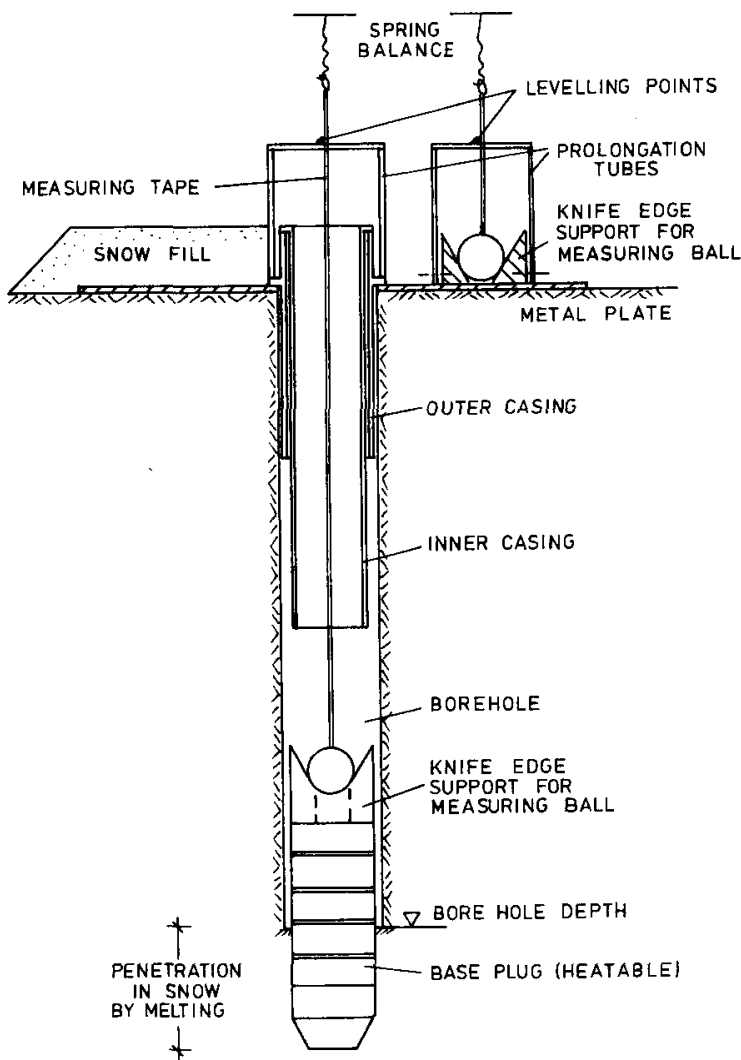

Fig.2(a). Schematic drawing of the measuring device for long-term observations of vertical deformation.

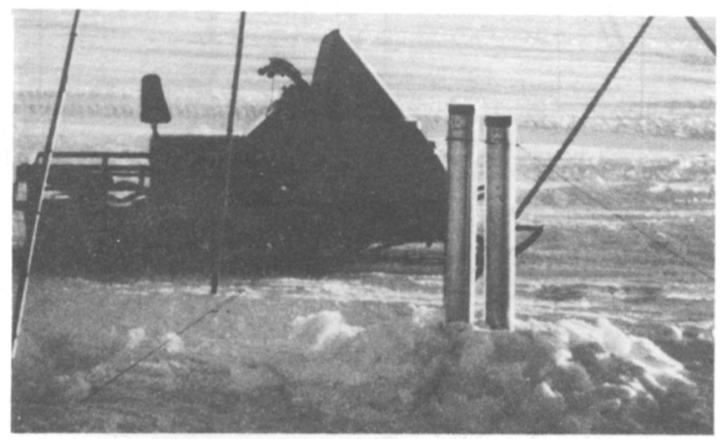

Fig.2(b). Measuring device after installation. iometer are the base plug at the bottom of the bore hole and the upper metal plate which is placed on the snow surface during installation. After drilling the bore hole to the desired depth the base plug is placed at the bottom of the bore hole and heated electricaliy. As the firn melts the plug sinks down for about $20 \mathrm{~cm}$. After the electric heating source is switched off the plug becomes frozen into the surrounding snow. The bore hole itself is lined with tubes of different diameter which act as telescope casings to permit free vertical movement of the snow and firn without hindrance. The casings are attached to the upper metal plate which serves as the boundary of the firn layer under consideration; the lower boundary is marked by the base plug.

Additional tubes are fixed to the upper side of the metal plate. These tubes will be extended in succeeding years to the new snow surface providing access for measuring to the base plug and to the metal plate. The distance from the base plug and the metal plate, respectively, to the top edge of the extension tubes will be measured by a calibrated tape which has a heavy metal ball on the lower end, which rests on the knife-edge support of the base plug. The tension of the measuring tape is controlled by a spring balance at its upper end.

These measuring devices have been installed at ten sites ( $P 1$ to $P 10)$, and in four reference points (F1 to F4, see Fig.3). The sites are located partly underneath and partly outside the buildings. The reference points, however, are positioned at a distance of $100 \mathrm{~m}$ from the station to ensure that the buildings do not exert any influence on the measurements.

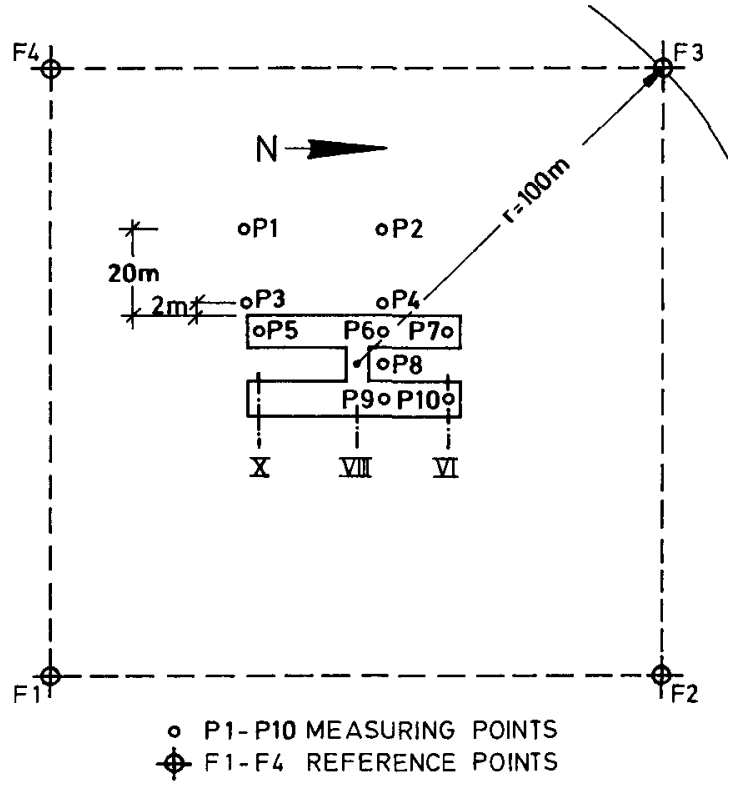

Fig.3. Position of measuring and reference points near Georg von Neumayer station.

The measurement of the vertical deformation of two snow/firn layers of different thicknesses is shown in Figure 4. Loads due to snow accumulation or to structure dead-weights generate time-dependent vertical deformation by compaction of the snow. Immediately after the installation and after a certain time interval the distance between the base plug and the upper metal plate is measured, and the difference $\Delta h$ of the two readings can be taken as the vertical deformation of one snow layer $\left(\Delta h=h-h^{*}\right)$.

This value $\Delta h$ represents the deformation of the whole snow and firn layer between the base plug and the metal plate. The time-dependent variation of $\Delta h$ is caused by the loads and the rheological behaviour of the material. In this way the $\Delta h$ data incorporate 


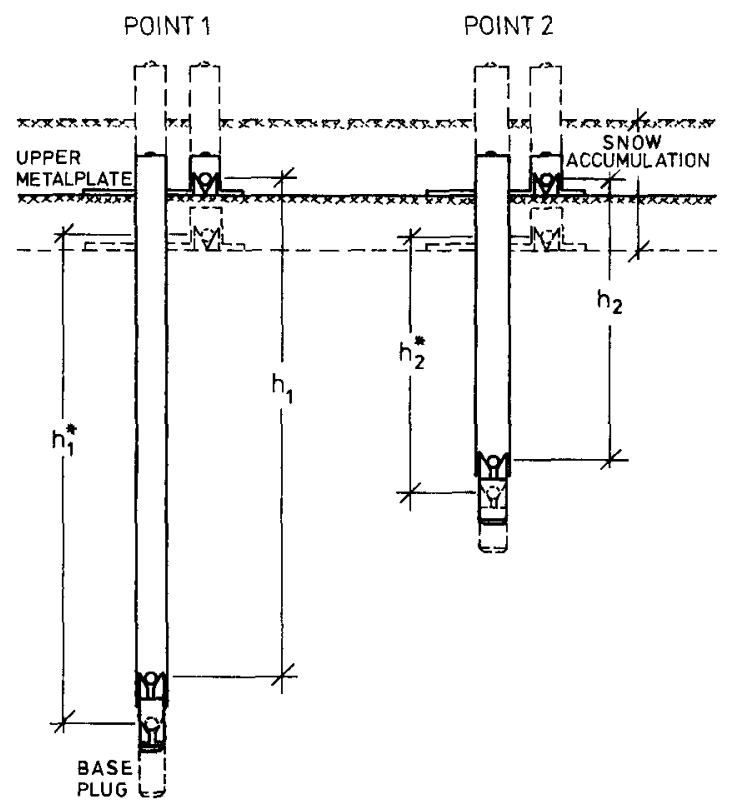

Fig.4. Description of deformation measurements.

all processes that occur in situ, but cannot be simulated in laboratory tests. Additionally the station buildings act as loads one order of magnitude greater than the annual accumulation, so that densification is faster than it would be with normal snow accumulation outside the station, for example at the reference points.

Every year at least these measureinents will be repeated. From the measured deformation the change of the mean density of the snow/firn layer under consideration and the rheological properties of the upper ice shelf layers can be calculated.

To measure settling rates from the station buildings during the winter period, when the reference points outside the station cannot be reached, measuring scales are installed in ten cross-sections on the side walls of the main tubes.

\section{FORMULATION OF THE DEFORMATION BEHAVIOUR}

When considering the time-dependent compression behaviour of ice-shelf ice, the Burgers model (Fig.5), which is a combination of a Maxwell unit and a Voigt

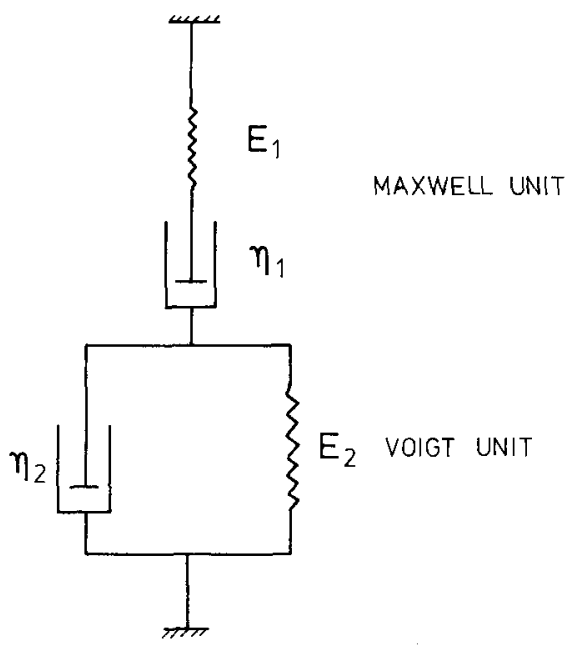

Fig.5. Burgers mode1. unit can be used (Bader 1962, Mellor 1975). The deformation derived from this model is

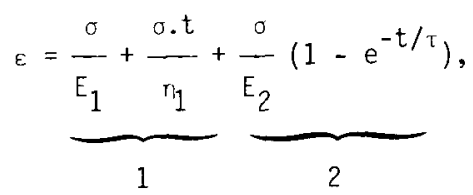

where $\sigma$ is the load, $E_{1}$ the spring constant of the Maxwell mode1 approximately equal to Young's modulus of the snow, $E_{2}$ the spring constant of the Voigt unit, $\eta 1$ the viscosity, $t$ the time, and $\tau$ the reference time. In this equation, part 1 is related to the deformation of the Maxwel1 unit and part 2 to the relaxation deformation of the Voigt unit. This later part can be neglected with regard to long periods (Bader 1962). It is assumed also that the instantaneous elastic deformation $\varepsilon=\sigma / E_{1}$ can be neglected because of the magnitude of the modulus of elasticity $E_{1}$ appropriate to the snow density of the upper zone of the Ekstrym Ice Shelf (Mellor 1975, Jessberger and Dörr 1981). For the given conditions (small load, high modulus of elasticity, sufficient loading time) only the viscous deformation $\varepsilon=\sigma . t / n_{1}$ remains and this depends linearly on the time and inversely on the compressive viscosity $n 1$.

Ramseier and Pavlak (1964) reported experimental results for the compressive viscosity (Fig.6), which, according to Haefeli and Brandenberger (1968), can also be calculated for a distinct location from the depth-density relation. Appropriate viscosity values calculated by the authors for Georg von Neumayer station are plotted in Figure 6. These data compare reasonably well with the $n^{-\rho}$ relation for Byrd station.

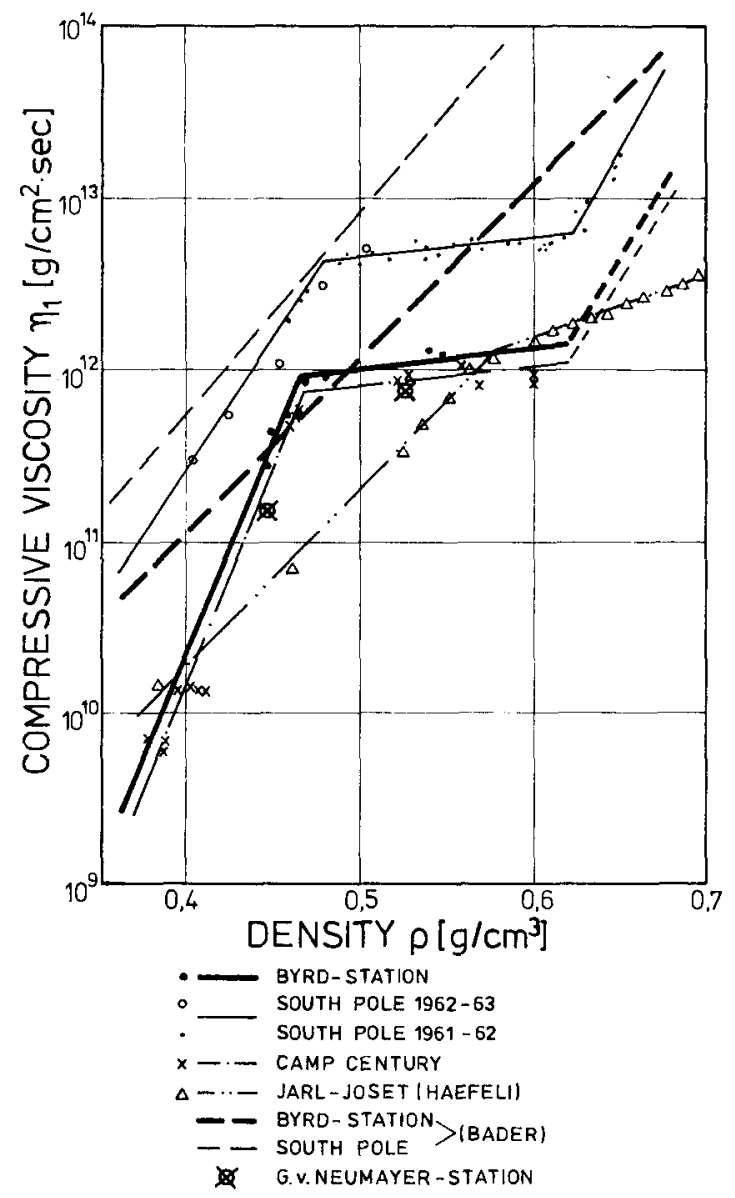

Fig.6. Compressive viscosity vs density (Ramseier and Pavlak 1964). 
4. CALCULATED AND MEASURED VERTICAL DEFORMATIONS

The following discussion refers to the east tube of the station, which has a ground area of about $50 \times 8 \mathrm{~m}$ and a foundation pressure of roughly $50 \mathrm{kPa}$. Because of the viscous properties of snow and firn the vertical deformation of the layers underneath the tube will increase with time. During the Antarctic winter and summer of 1981-82 this behaviour was determined by measuring the differential settlement of the tube.

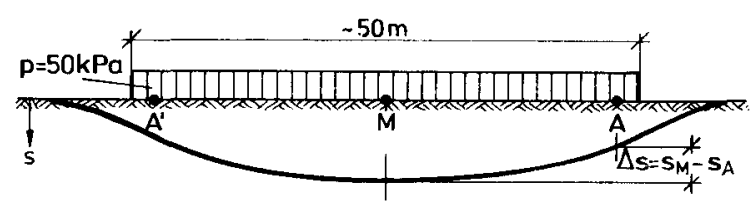

a)

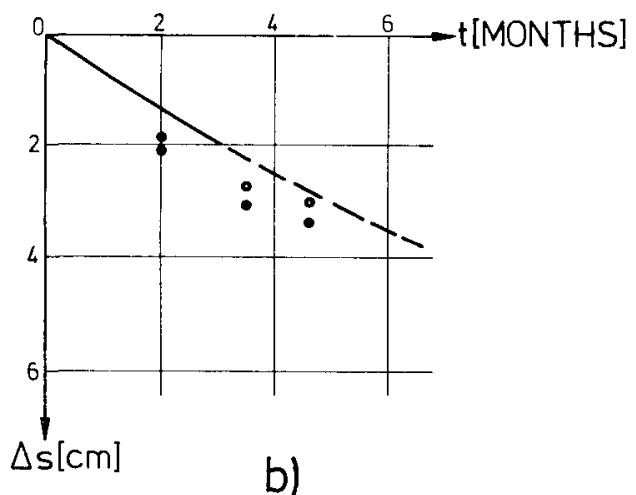

Fig.7. (a) Generalized settlement curve.

(b) Jime-dependent differential settlements.

The centre point $M$ of the ground area in Figure 7 (a) corresponds to cross-section VIII in Figure 3 , the outer points $A$ and $A^{\prime}$ correspond to crosssections $V I$ and $X$ respectively. In Figure $7(b)$ the measured differences in the settiement of the tube are shown. The open and full circles belong to the differential settlement $\left(S_{M}-S_{A}\right)$ and $\left(S_{M}-S_{A^{\prime}}\right)$ respectively.

The calculation of the settlement of the tube at point $M$ and $A$ has been performed in the following way (Fig.8). The stress distribution versus depth was calculated according to Boussinesque down to the depth $z=20 \mathrm{~m}$. The viscous strain $\varepsilon_{j}$ of any chosen layer $i$ is calculated to be

$$
\varepsilon_{i}=\sigma_{z i} \cdot t / \eta_{1}(i)
$$

where $\sigma_{z i}$ is the vertical stress in the middle of layer $i, t$ the time, and $n_{1}(i)$ the compressive viscosity depending on density (see Fig.6). The total settling of each point is

$$
s=\sum_{i} \varepsilon_{i} \cdot \Delta z_{i}
$$

The different vertical stress distribution underneath $M$ and $A\left(A^{\prime}\right)$, leads to the differential settlings

$$
\Delta s=S_{M}-s_{A}
$$

given in the line of Figure $7(b)$.

It should be mentioned that the vertical deformation of the firn causes an increase of density followed by an increase in viscosity. However, during the period of observation, so far, this change is not yet significant so that the assumption that the viscosity has been constant should be acceptable. The differences between the calculated and the measured $\Delta s$ values are caused by the assumption made for the calculation and also by the procedure of the station construction. The comparison between calculated results and these first measurements is encouraging. These vertical deformation measurements, therefore, together with vertical magnetic probe extensiometer readings and inclinoneter readings in special grooved deformable casings will be included in long-term observations made at the station.

\section{ACKNOWLEDGEMENTS}

The financial support of the Bundesminister für Forschung und Technologie (BMFT) and the Deutsche Forschungsgemeinschaft (DFG) as well as the cooperation of $N$ Diekmann, $P$ Jordan, and $O$ Bangel are gratefully acknowledged.

\section{REFERENCES}

Bader H, Kuroiwa D 1962 The physics and mechanics of snow as a material. Cold Regions Researeh and Engineeming Laboratory. Monograph II-B

Haefeli R, Brandenberger $F \quad 1968$ Rheologischglaziologische Untersuchungen im Firngebiet des grönländischen Inlandeises. Meddelezser on Gron Zand 177(1)

Jessberger $H L$, Dorr R 1981 Untersuchung des

Bruch- und Verformungsverhaltens von antarktischem Schelfeis. Bautechnik 11(58): 388-394

Mellor M 1961 The Antarctic ice sheet. Cold Regions Research and Engineering Laboratory. Monograph I-BI

Mellor M 1975 A review of basic snow mechanics. Intemational Association of Hydrological Soiences Publication 114 (Symposium of GrindeTwald 1974 Snow Mechanies): 251-291

Ramseier R O, Pavlak T L 1964 Unconfined creep of polar snow. Journal of Glaciology 5(39): 325-332 Reinwarth 0, Rauert W, Stichler W, Moser H 1982 Preliminary investigations on accumulation at the Filchner/Ronne ice shelves and Atka Bay. Annals of Glaciology 3: 274-278
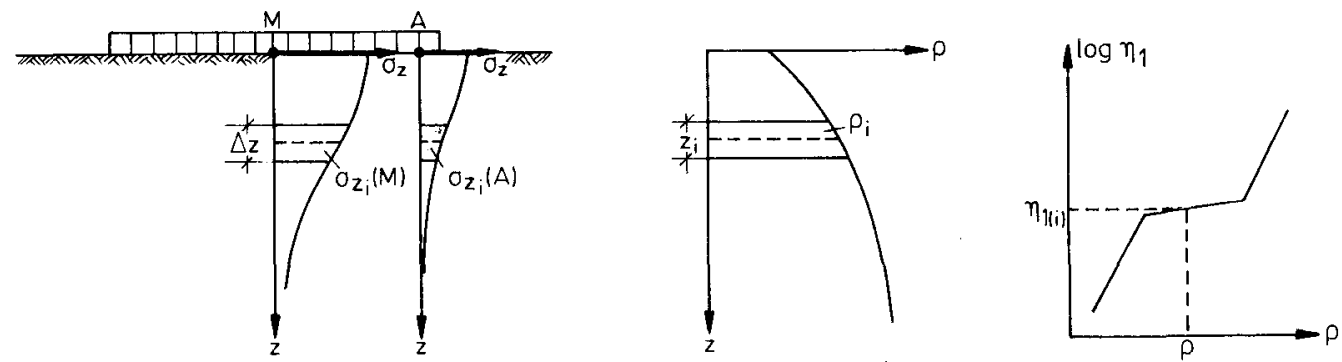

Fig.8. Process of calculation of settlements under loads on a viscous medium. 